\title{
RESISTIN GENE POLYMORPHISM IN OFFSPRING OF PATIENTS WITH TYPE 2 DIABETES MELLITUS
}

\author{
Farid Fawzy (1), Osama Khalil (1), Hatem M. Salem (1), Mohamed S. Fawzy (2)
}

(1) Department of Internal Medicine, Faculty of Medicine, Zagazig University, Egypt.

(2) Department of Medical Biochemistry, Faculty of Medicine, Zagazig University, Egypt.

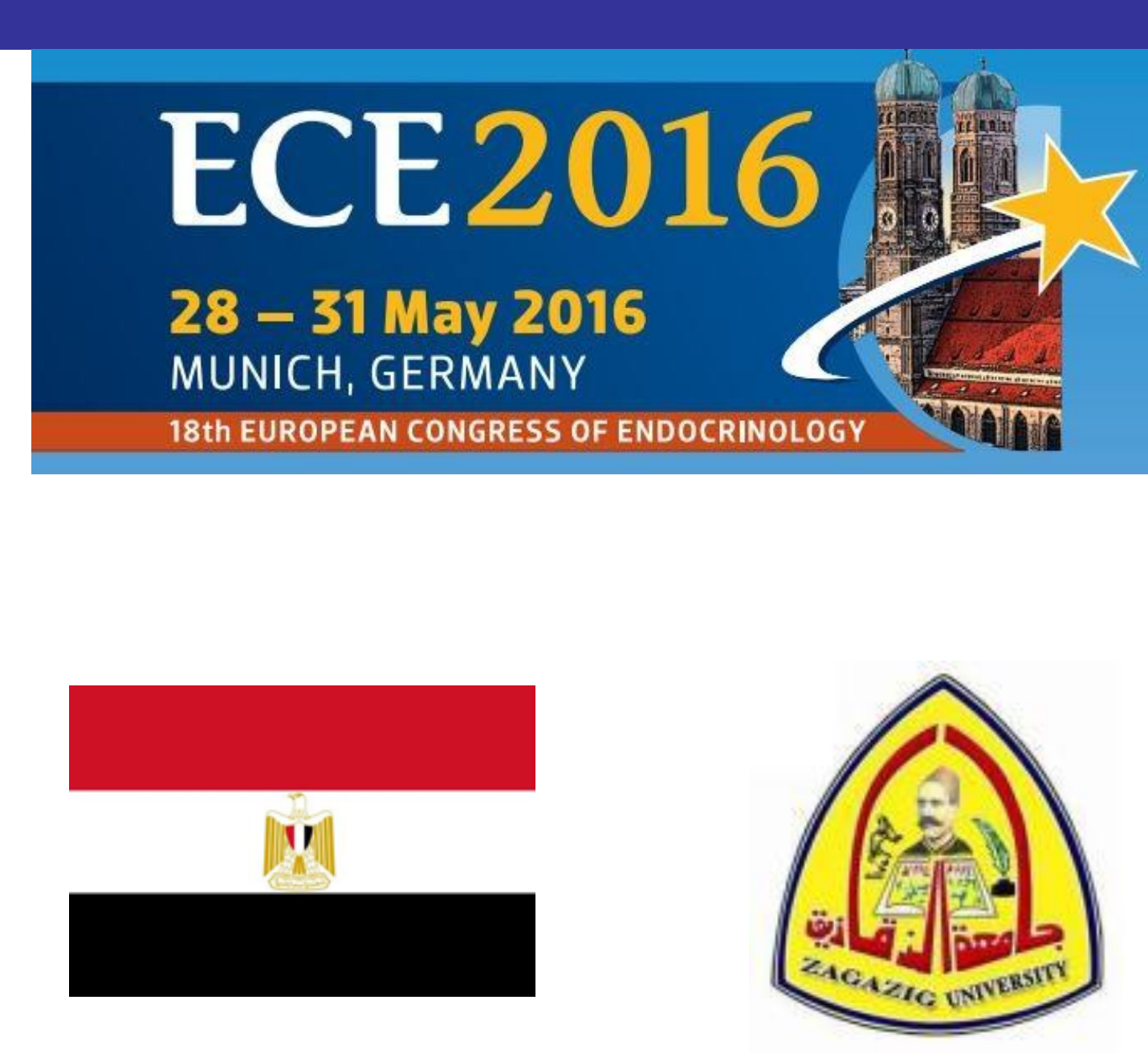

\section{OBJECTIVES}

Background: Resistin is a hormone that potentially links obesity to T2DM. Several Single Nucleotide Polymorphisms (SNPs) have been identified in the Resistin Gene (RETN). Polymorphism of RETN +299 $(\mathrm{G}>\mathrm{A})$ may contribute to increased resistin levels, which may be involved in the pathogenesis of T2DM ${ }^{1}$.

Aim of work: To study the association between resistin gene +299 polymorphism and insulin resistance in non-diabetic offspring of T2DM.

\section{METHODS}

Methods: This case control study included 60 volunteers divided into 2 groups:

Group A: Control group including 30 healthy individuals with negative family history of DM. Group B: Offspring of patients with T2DM including 30 non-diabetic individuals with positive family history of DM. The latter group was further classified after OGTT into:

Group B1: 15 individuals with normal glucose tolerance.

Group B2: 15 individuals with impaired glucose tolerance.

All individuals had an estimation of serum resistin level by ELISA and RETN+299 polymorphism by Polymerase Chain Reaction-Restriction Fragment Length Polymorphism (PCR-RFLP) (Table 1).

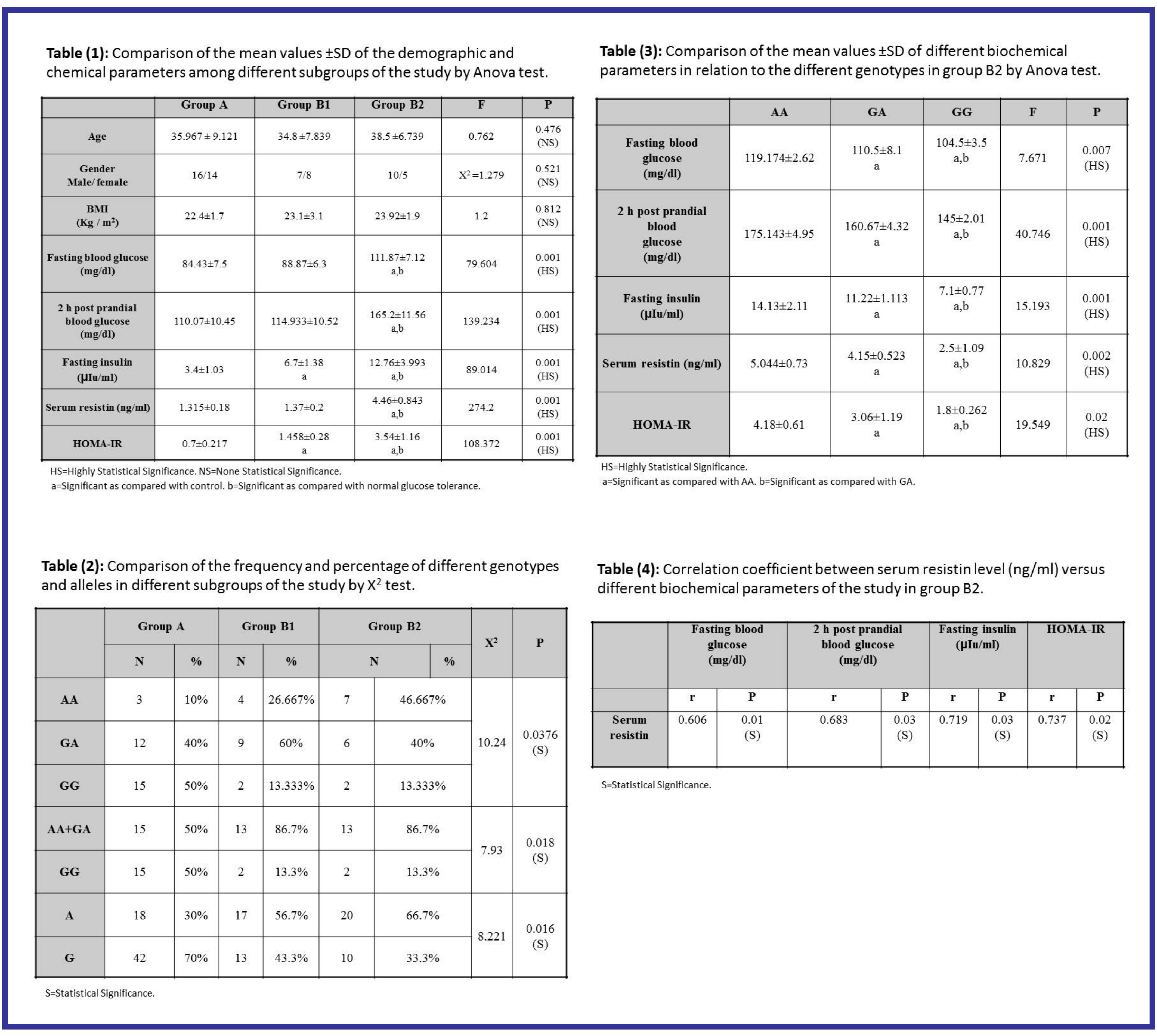

\section{RESULTS}

Results: We found a statistically significant increase of serum resistin (AA genotype and combined GA+AA genotypes), decrease in GG genotype, increase of $A$ allele $(P<0.03)$ and increase in the indices of insulin resistance in the impaired glucose tolerant offspring as compared to the control individuals as well as normal glucose tolerant offspring (Table 2).

There was also a statistically significant association between hyperglycemia and resistin gene polymorphism at positions +299 $(\mathrm{G}>\mathrm{A})$ (Table 3).

Moreover, a significant positive correlation was found between serum resistin level and insulin resistance in impaired glucose tolerant offspring (Table 4).

\section{CONCLUSIONS}

Conclusions: The present study support that RETN+299 G>A SNP and increase in serum resistin may have contributed to increased insulin resistance with subsequent susceptibility to T2DM in offspring of type 2 diabetic patients. Those carrying AA and combined GA+AA genotypes are more at risk.

\section{References}

Khalil O, Alnahal A, Ghonium M. et al., (2014): Does Resistin Gene Polymorphisms $+299 \quad(G>A)$ Participate in Insulin Resistance in Egyptian non-Obese Type 2 Diabetes? Int $J$ Genomic Med ; 2: 117-123. 